\title{
Study on the Effect Influence Factors and the Optimal Operating Conditions to Treat the High Ammonia-Nitrogen Wastewater by SDMBR
}

\author{
Zhi-yong HAN*, Bao-chuan QI, Ling LI, Yan KONG and Kun HAN \\ School of Petrochemical Lan Zhou university of Technology. Lan Zhou, Gan Su China, \\ Email:Hanzhy_009@sina.com
}

\begin{abstract}
The Sequencing dynamic membrane bioreactorSDMBR was proposed and adopted in this study to treat the high ammonia-nitrogen wastewater according to the features of its wide sources, large emission, high difficulty to be treated and easily lead to serious eutrophication etc. Then, the effluence factors including HRT,MLSS,DO, and $\mathrm{pH}$ values, the treatment effect, And the optimum operating conditions of the reactor were deeply researched and analyzed by the single element, orthogonal experiments and the range analysis ,the results were as following, Firstly, the period for the sludge acclimation and to start successfully of the SDMBR was 30 days, and the reactor has high treatment efficiency in this period with high ammonia nitrogen removal rate of more than $90 \%$ with the influent ammonia nitrogen Concentration of $130 \mathrm{mg} / \mathrm{L}$, Then, the single factor experiments including MLSS,DO,HRT and pH value were designed and operated and the optimum operating conditions were got as the MLSS, DO, HRT and pH value were $4000 \sim 6000 \mathrm{mg} / \mathrm{L} 2 \sim 4 \mathrm{mg} / \mathrm{L} \quad 12 \mathrm{~h} \sim 18 \mathrm{~h}$ and7 9 respectively. Thirdly, through orthogonal test and range analysis to HRT, MLSS, DO and $\mathrm{pH}$ value, the experiment obtained that, according to influence degree, the 4 above-mentioned factors influencing on COD removal rate were sorted by HRT, MLSS, DO and $\mathrm{pH}$ value in descending order, and the operating parameters of HRT, MLSS, DO and $\mathrm{pH}$ value were $18 \mathrm{~h}, 5 \mathrm{~g} / \mathrm{L}, 4 \mathrm{mg} / \mathrm{L}$ and $7-9$ respectively.Finally, through orthogonal test and range analysis to HRT, MLSS, $\mathrm{DO}$ and $\mathrm{pH}$ value, the optimal operating parameters of the SDMBR were $\mathrm{pH}$ value of $8, \mathrm{DO}$ of $4 \mathrm{mg} / \mathrm{L}, \mathrm{MLSS}$ of $5 \mathrm{~g} / \mathrm{L}$ and HRT of 15h to treat the high ammonia-nitrogen wastewater. And the average total removal rates of COD,NH4+-N,TN under this optimal operating parameters were $94.64 \%, 95.31 \%$ and $77.62 \%$ respectively
\end{abstract}

Keywords-Sequencing dynamic membrane bioreactor; high ammonia-nitrogen wastewater; optimal running conditions

\section{INTRODUCTION}

The water eutrophication has been one of the global problems since the 1960s of the 20th century, and it Leaded to increasingly serious environmental problems in global range, the Nitrogen and phosphorus pollution in water was increasingly serious after the 1980s of the 20th century, especially the Mass emission of the high concentration ammonia nitrogen wastewater from the Coking, chemical fertilizer, petrochemical, chemical, metallurgy, food farming industry and the landfill leachate etc., and it has been an important and difficult problem of the environment protection field and attracted the attention of many experts , so, to explore a fast efficient and economical nitrogen and phosphorus nutrition material removal method or process would has high of theory and practical significance, in view of this ,a new self-designed Sequencing dynamic membrane bioreactor was proposed and selected to treat the high concentration ammonia nitrogen wastewater, and its influence factors and the optimal operating conditions has been investigated deeply inorganic In order to get some early exploration and improvement for its engineering application

\section{MATERIALS AND METHODS}

\section{A. Materials}

(1)Sludge: From the Sewage treatment plant of Lan Zhou

(2)Membrane: Stainless steel wire mesh flat membrane:(200 mesh)

(3) reactor: A Plexiglass container(4L)

\section{B. Experiment Devices}

The SDMBR reactor which was self- designed as shown in fig. 1 which was made up of the influent tank, Aeration device, dynamic membrane bioreactor, electronic control systems and temperature control devices etc.

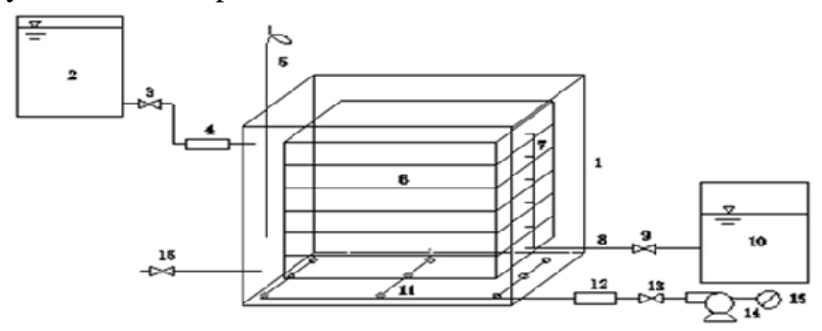

Fig.1 Schematic diagram of the SDMBR experiment apparatus

Dynamic membrane bioreactor2. Influent tank 3. Water switch 4. Flow meter 5. Temperature control device 6. Membrane module 7. Water branch pipe 8.Water header 9.Effluent switch 10.Effluent tank 11.Micro-pore aerator 12.Rotor flowmeter13. Air control valve 14. Air compressor 15.Time control device 16 Sampling port

The reactor was a $4 \mathrm{~L}$ Cuboid Plexiglass container and the membrane module was the 200 mesh stainless steel wire mesh flat membrane there're 5 layers membranes with the 
area $0.025 \mathrm{~m} 2$ of each one. they have the same height and were arranged in parallel inside the reactor,9 micro-porous aerator were installed equidistantly at the bottom of the reactor which improve the surface cross flow rate and enhanced the uniformity of flow state of the reactor, and reduced the area of the dead reaction zone, the high ammonia-nitrogen wastewater flowed into the system by sequencing way and emerged turbulent flow under the presence of aeration which lead the high ammonia-nitrogen wastewater full accessing to the Suspended sludge, part of the organic matter was removed by the degradation of the activated sludge microorganisms in the suspended sludge, then in the presence of concentration polarization the dynamic bio- membrane with double functions of effective blocking and biodegradable was formed at the surface of the stainless steel wire mesh film which could remove most of the organic pollutions when the mixture of the sludge and wastewater flowed through it, the Outlet was located at the bottom of the reactor, the effluent flowed by gravity because of the level of high ammonia wastewater in the reactor and the water outlet difference

\section{EXPERIMENTS AND RESULTS}

\section{A. Ammonia Nitrogen Removal Efficiency}

The ammonia-nitrogen, as the main pollution factor, its removal effect during the SDMBR acclimation period were determined and analyzed and the results as shown in Figure 2.

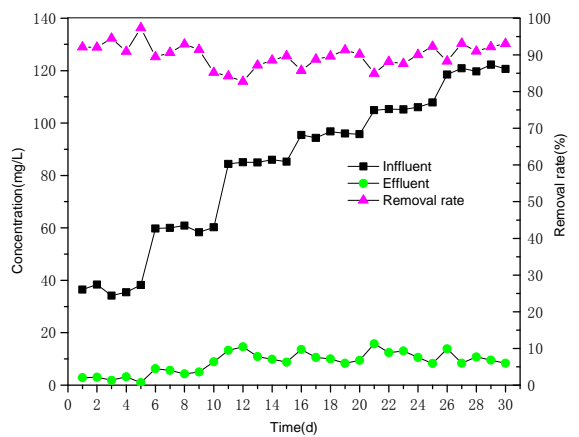

Fig.2. Varieties of concentration and the removal rates of the NH4+-N

As shown in Fig2, we would know that the SDMBR could keep very high removal rate to the ammonia-nitrogen during the whole acclimation period, and the ammonianitrogen concentration of the effluent could maintain $2.01 \sim 11.39 \mathrm{mg} / \mathrm{L}$ when the influent ammonia-nitrogen concentration was $118.4 \sim 140.3 \mathrm{mg} / \mathrm{L}$, and the average one was $6.12 \mathrm{mg} / \mathrm{L}$ which meanded the average removal rate of the ammonia-nitrogen could reach $95.31 \%$. the ammonianitrogen concentrations of the supernatant Was between $2.25 \sim 11.92 \mathrm{mg} / \mathrm{L}$ and the average one was $7.00 \mathrm{mg} / \mathrm{L}$, The results indicated that :The bio-removal rate of the ammonianitrogen was94.58\% and the membrane blockage one was only $0.06 \% \sim 3.23 \%$.thus, the reactor had very good ammonia-nitrogen removal efficiency, at the same time, the contribution of the membrane intercept and filter to the ammonia nitrogen removal is very small because the ammonia nitrogen belongs to small molecules and it could pass through the membrane freely, so, the ammonia nitrogen removal effect ammonia nitrogen mainly owed much to the large number of nitrifying bacteria accumulation on the biofilm.

\section{B. COD Removal Efficiency}

After the acclimation, the system entered into a stable operation period. During this period, the removal efficiency of $\mathrm{TN}, \mathrm{NH}_{4}{ }^{+}-\mathrm{N}$ and $\mathrm{COD}$ in wastewater was studied. The test results were shown in Figure 3, 4, 5, respectively.

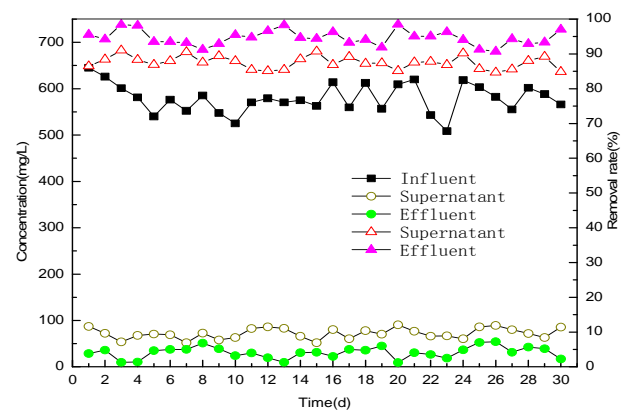

Fig.3 Varieties of the concentration and removal rations of the COD

As shown in Fig3, in the stable operation stage, the whole system of SDMBR reactor is better for COD removal. When the influent COD concentration in the 508.7 to $645.1 \mathrm{mg} / \mathrm{L}$ interval changes; effluent COD concentration in 9.13 to $54.18 \mathrm{mg} / \mathrm{L}$ within the range of variability, the mean is $31.02 \mathrm{mg} / \mathrm{L}$; visible reactor of COD total removal rate to maintain a high level, the average total removal rate is as high as $94.64 \%$. The supernatant COD concentration was in the range of $52.14 \sim 90.56 \mathrm{mg} / \mathrm{L}$, the mean value was $72.13 \mathrm{mg} / \mathrm{L}$, the biological removal rate was about $87.55 \%$, and the removal rate of the membrane was about 3.15\% $10.95 \%$.

Thus, SDMBR reactor has a good removal effect on the organic matter. This mainly comes from two aspects: Biofilm process has a higher concentration of activated sludge compared with traditional activated sludge process, which contributes to the removal of organic matter enhance the biodegradation, the organic matter removal with. On the other hand, macromolecules are retained by membrane components and filter membrane layer and filtration layer formed by sludge formation. This ensures a very low effluent concentrations of pollutants and water stability. 


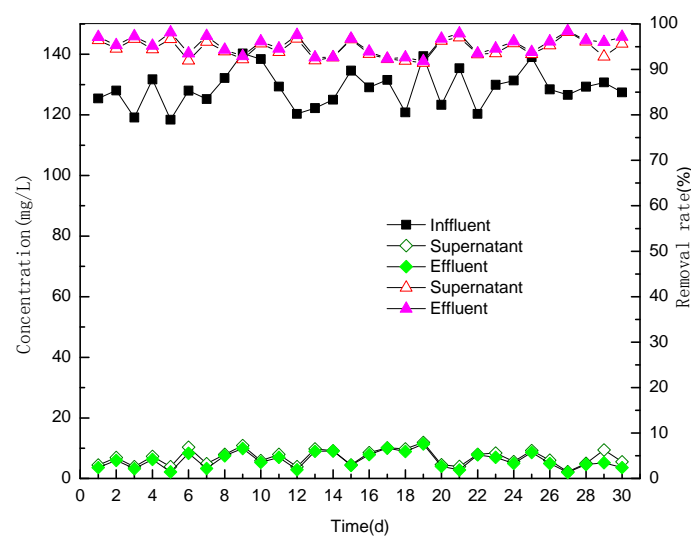

Fig.4 Varieties of the concentration and removal rations of the $\mathrm{NH} 4+-\mathrm{N}$

As shown in Fig4, the SDMBR reactor works well in the stable operation of theNH${ }_{4}^{+}$-Nremoval. Inlet concentration of $\mathrm{NH}_{4}{ }^{+}-\mathrm{N}$ in the $140.3 \mathrm{mg} / \mathrm{L}$ within the range of of 118.4 to belongs to the high concentration of ammonia nitrogen wastewater, effluent concentration of $\mathrm{NH}_{4}{ }^{+}-\mathrm{N}$ in $2.01 \sim$ $11.39 \mathrm{mg} / \mathrm{L}$ within the range of variability, the mean is $6.12 \mathrm{mg} / \mathrm{L}$; the total removal rate of $\mathrm{NH}_{4}{ }^{+}-\mathrm{N}$ remained at a high level, the average total removal rate was $95.31 \%$. The concentration of $\mathrm{NH}_{4}{ }^{+}-\mathrm{N}$ in supernatant was changed in the range of $2.25 \sim 11.92 \mathrm{mg} / \mathrm{L}$, the mean value was $7.00 \mathrm{mg} / \mathrm{L}$, and the biological removal rate was about94.58\%, the removal rate of the membrane was $0.06 \% \sim 3.23 \%$.

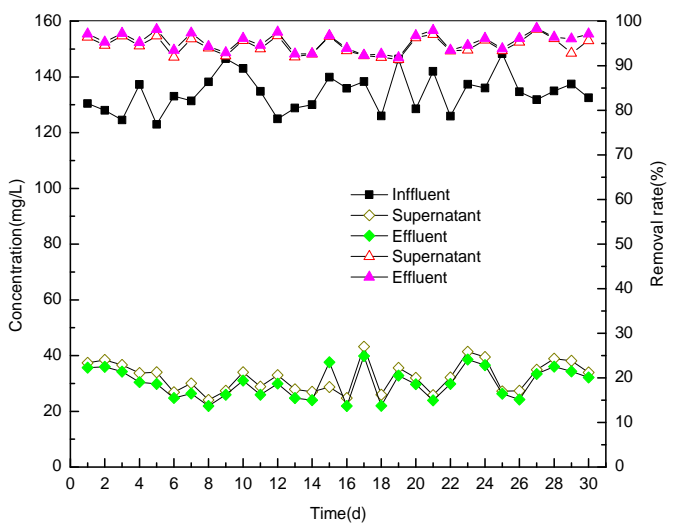

Fig.5 Varieties of the concentration and removal rations of the TN

As shown in Fig5, The TN removal effect of the SDMBR reactor in the stable operation stage is significantly enhanced. The influent TN concentration was changed in the range of $122.9 \sim 148.3 \mathrm{mg} / \mathrm{L}$, and the TN concentration of the effluent was changed in the range of $21.93 \sim$ $39.81 \mathrm{mg} / \mathrm{L}$, the mean value was $30.00 \mathrm{mg} / \mathrm{L}$, the average total removal rate was $77.62 \%$. The concentration of TN in supernatant was changed in the range of $24.09 \sim 43.19 \mathrm{mg} / \mathrm{L}$, the mean value was $32.3 \mathrm{mg} / \mathrm{L}$, the biological removal rate was about $75.88 \%$, and the removal rate of the membrane was about $0.61 \% \sim 3.13 \%$. The TN concentration in the reactor effluent was similar to the TN concentration in the supernatant, and the difference was not significant, which showed that the interception function of the membrane had no significant effect on the removal of TN.

\section{Study on Influencing Factors of SDMBR Reactor}

Four factors, MLSS, DO, HRT and $\mathrm{pH}$ were selected to study the effect of SDMBR reactor on the removal efficiency of COD and NH4+-N in high ammonia nitrogen wastewater under different conditions. And an in-depth comparison of orthogonal experiment analysis and differential impact of the above factors.

1) Effect of MLSS on the removal of COD and NH4+-N

Experimental control of $\mathrm{pH}$ value is about 7.5, water temperature between 20 to $23^{\circ} \mathrm{C}$, hydraulic retention time is $12 \mathrm{~h}$, aerobic $8 \mathrm{~h}$ and anaerobic $4 \mathrm{~h}, \mathrm{DO}$ at around $2 \mathrm{mg} / \mathrm{L}$, MLSS changes between the $1469 \mathrm{mg} / \mathrm{L}$ and $8922 \mathrm{mg} / \mathrm{L}$, COD and $\mathrm{NH}_{4}{ }^{+}-\mathrm{N}$ removal rate effect were studyed, as shown in Fig 6 and Figure 7.

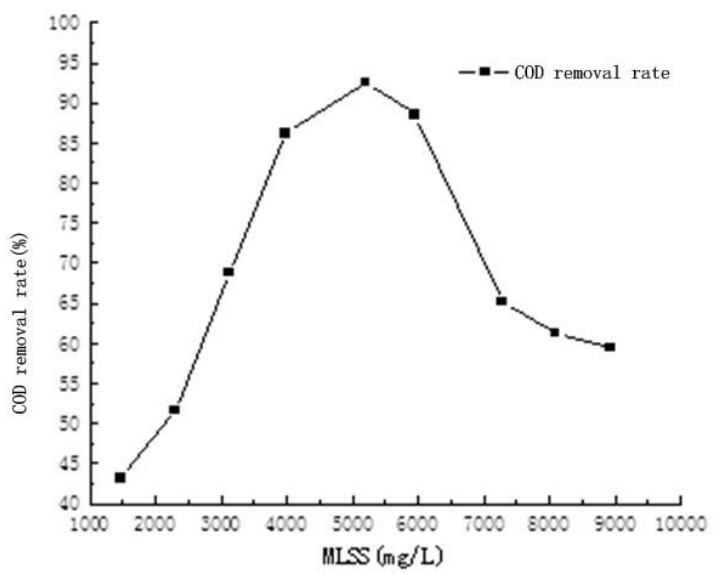

Fig.6 The changes of COD removal rate under different MLSS concentrations

Figure 6 shows the change of COD removal rate under different MLSS. With the increasing of COD, the removal rate of MLSS increases at first and then decreases, and $5209 \mathrm{mg} / \mathrm{L}$ is the turning point of the removal rate. When MLSS was in low concentration $(<3127 \mathrm{mg} / \mathrm{L})$, the removal rate of COD was less than $70 \%$. When MLSS was in high concentration $(>3127 \mathrm{mg} / \mathrm{L})$, the removal rate of COD increased rapidly, reaching a maximum of $92.1 \%$. When MLSS continued to increase to $7281 \mathrm{mg} / \mathrm{L}$, the COD removal rate dropped to $65 \%$. 


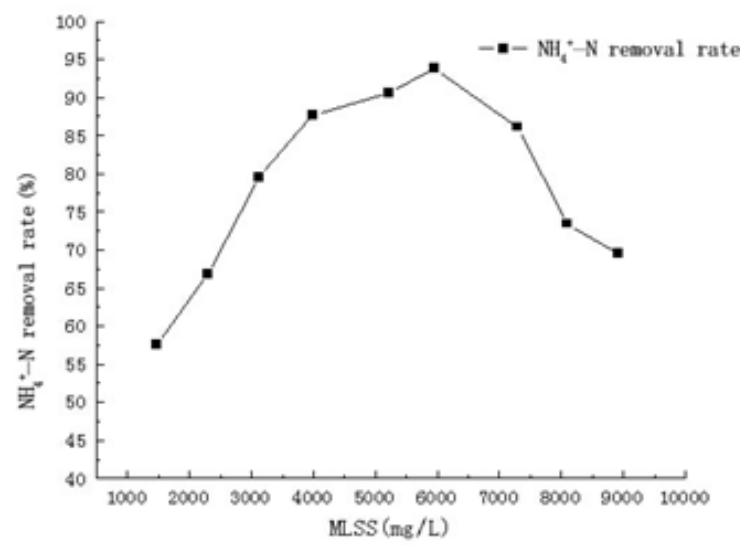

Fig.7 The changes of NH4+-N removal rate under different MLSS concentration

From Fig. 7, with the increase of MLSS, $\mathrm{NH}_{4}{ }^{+}-\mathrm{N}$ removal rate was firstly increased and then decreased, which MLSS concentration of $5954 \mathrm{mg} / \mathrm{L}$ is the trend turning point. When the MLSS concentration is $5954 \mathrm{mg} / \mathrm{L}, \mathrm{NH}_{4}{ }^{+}-\mathrm{N}$ removal rate was increased from $57.6 \%$ to $93.61 \%$. When the MLSS concentration is $8922 \mathrm{mg} / \mathrm{L}, \mathrm{NH}_{4}{ }^{+}-\mathrm{N}$ removal rate was decreased to $69.56 \%$.It may be due to the system provide insufficient dissolved oxygen system for nitrobacteria. while in the absence of a high concentration of sludge MLSS, nitrifying bacteria will be suppressed microbial secretory products thus affecting the efficiency of nitrification.

2) Effect of DO on the removal of COD and NH4+-N

According to the effect of MLSS on COD and $\mathrm{NH}_{4}{ }^{+}-\mathrm{N}$ removal rate, The following experiments determined the MLSS, pH , water temperature, HRT and aerobic 8h + anaerobic 4h, detection DO concentration control between $0.97 \mathrm{mg} / \mathrm{L} \sim 4.72 \mathrm{mg} / \mathrm{L}$ change ,the influence of DO concentration on COD and NH4 + -N removal was studied, the results shown in Figure 8. Figure 9.

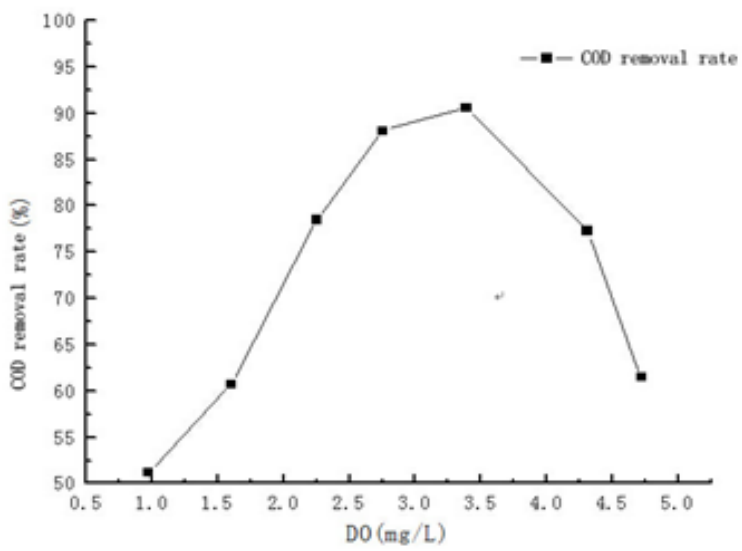

Fig.8 The changes of COD removal rate under different DO concentration
As shown in Fig. 8, when the dissolved oxygen concentration increased from $0.97 \mathrm{mg} / \mathrm{L}$ increased to $2.25 \mathrm{mg} / \mathrm{L}$, COD removal rate rapidly increased from $51.2 \%$ to $78.5 \%$.But with the dissolved oxygen concentration continued to increase, resulting in the removal rate of COD rise slows with the DO concentration increasing. when the dissolved oxygen increased more than 3.39mg / L, COD removal efficiency decreased. The main cause of fluctuations in the data is that the removal of COD mainly by activated sludge aerobic bacterial degradation, and low dissolved oxygen concentration on the activity of aerobic bacteria have different degrees of inhibition, with the continuous improvement of dissolved oxygen, aerobic bactericidal activity into full play, but too high too fast increase dissolved oxygen concentration will also increase the flow shear stress, is not conducive to organic compounds adsorbed onto the surface of activated sludge, thus reducing the incidence removal.

According to the results the effect of MLSS and dissolved oxygen removal rate of COD and $\mathrm{NH}_{4}{ }^{+}-\mathrm{N}$, The optimum operation conditions were determined as following: MLSS is $5000 \mathrm{mg} / \mathrm{L}, \mathrm{DO}$ is $3 \mathrm{mg} / \mathrm{L}$, $\mathrm{pH}$ is 7.5 , and the aerobic reaction time and anaerobic reaction time ratio is 2 : 1 .The HRT (6h, 8h, 12h, 15h and 18h) was studied in term of their effect on removal efficiency of COD and NH4+- N,as shown in Fig. 9, 10.

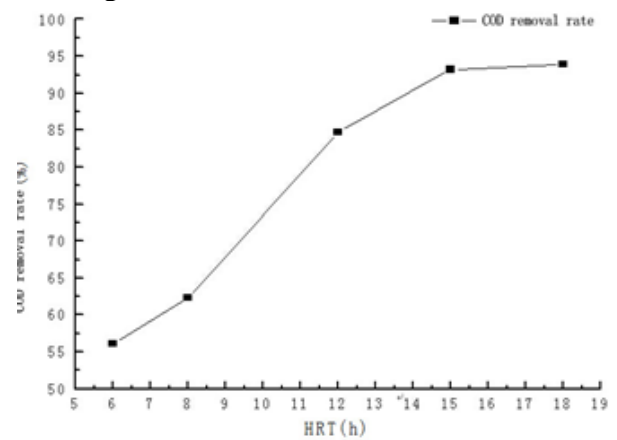

Fig. 9 The changes of COD removal rate under different HRT

As shown in Fig. 9, HRT has some influence on the removal rate of COD. When HRT was $6 \mathrm{~h}, \mathrm{NH}_{4}{ }^{+}$-Nremoval rate was only56.1\%, Along with the extension of HRT, the COD removal rate rapidly increased when HRT is $15 \mathrm{~h}$, COD removal rate reached a maximum value of $92.2 \%$. the main cause is that the degradation of organic matter in the sewage more thoroughly, reaction in COD is removal rate increased with the extension of HRT, but when the HRT is too long, with the constant consumption of nutrients in the reactor, microbial nutrient deficiencies, death, autolysis, thus increasing the COD removal rate slowly. 


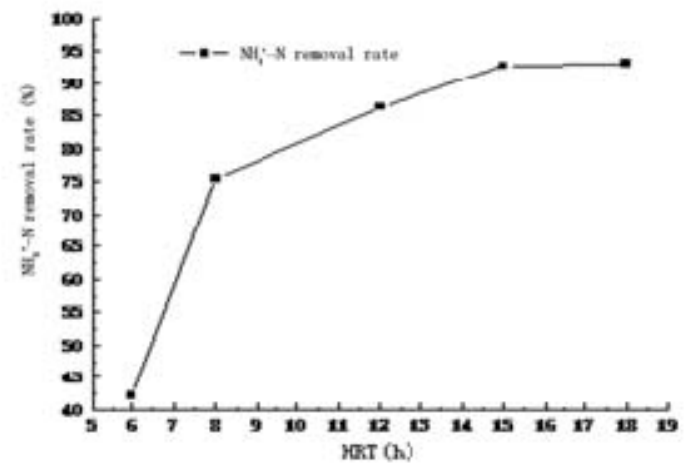

Fig. 10 The changes of NH4+-N removal rate under different HRT

As shown in Fig. 10, HRT has some influence on the removal rate of $\mathrm{NH}_{4}{ }^{+}-\mathrm{N}$. When $\mathrm{HRT}$ was $6 \mathrm{~h}, \mathrm{NH}_{4}{ }^{+}-\mathrm{N}$ removal rate was only $42.1 \%$, Along with the extension of HRT, $\mathrm{NH}_{4}{ }^{+}-\mathrm{N}$ removal rate rapidly increased when HRT is 15h, the maximum removal rate of $\mathrm{NH}_{4}{ }^{+}-\mathrm{N}$ was measured to $93.2 \%$. The mechanism ofNH${ }_{4}^{+}-\mathrm{N}$ removal is largely comprised of nitrification and denitrification,.short HRT is not enough to meet the time required for the bacterial reproduction, and then $\mathrm{NH}_{4}{ }^{+}-\mathrm{N}$ removal rate is low, and with the extension of HRT and the increase of nitrification bacteria, which is in favor of the rapid and efficient removal of ammonia nitrogen.

\section{Study on the Optimal Operating Conditions of the Reactor}

In order to determine the effect of each factor on the treatment of high ammonia nitrogen wastewater by SDMBR reactor, the four factors of HRT, MLSS, $\mathrm{pH}$ and DO factors were chosen to carry out the orthogonal experiment.

TABLE 1 ORTHOGONAL EXPERIMENTAL RESULTS

\begin{tabular}{lllll}
\hline Number & $\mathrm{pH}$ & HRT(h) & $\mathrm{DO}(\mathrm{mg} / \mathrm{L})$ & $\begin{array}{l}\text { MLSS(g/L } \\
\text { (1) }\end{array}$ \\
\hline 1 & 7 & 12 & 2 & 4 \\
2 & 8 & 15 & 3 & 5 \\
3 & 9 & 18 & 4 & 6 \\
\hline
\end{tabular}

According to the theory of orthogonal experiment, the four factors and three levels of the orthogonal test need to be carried out 9 tests, In order to improve the accuracy of the experiment, the experiment was repeated three times and the average value was gained. According to the range analysis to determine the effect of each factor on the experimental results, In order to improve the accuracy of the experiment, the experiment was repeated three times and the average value was taken. the results of the experiment are shown in table 2 , table 3 .
TABLE 2 ORTHOGONAL EXPERIMENTAL RESULTSOF COD

\begin{tabular}{|c|c|c|c|c|c|}
\hline Number & $\mathrm{pH}$ & $\begin{array}{l}\text { HRT(h } \\
\text { ) }\end{array}$ & DO & $\begin{array}{l}\text { MLSS( } \\
\mathrm{g} / \mathrm{L})\end{array}$ & $\begin{array}{l}\text { Removal } \\
\text { rate(\%) }\end{array}$ \\
\hline 1 & 7 & 12 & 2 & 4 & 91.06 \\
\hline 2 & 7 & 15 & 3 & 5 & 93.57 \\
\hline 3 & 7 & 18 & 4 & 6 & 92.98 \\
\hline 4 & 8 & 12 & 3 & 6 & 90.52 \\
\hline 5 & 8 & 15 & 4 & 4 & 93.83 \\
\hline 6 & 8 & 18 & 2 & 5 & 94.06 \\
\hline 7 & 9 & 18 & 4 & 5 & 93.21 \\
\hline 8 & 9 & 12 & 2 & 6 & 91.02 \\
\hline 9 & 9 & 15 & 3 & 4 & 90.55 \\
\hline K1 & 277.61 & 272.6 & 276.14 & 275.44 & \\
\hline K2 & 278.41 & 277.95 & 274.64 & 280.84 & \\
\hline K3 & 274.78 & 280.25 & 280.02 & 274.52 & \\
\hline $\begin{array}{l}\mathrm{k} 1=(\mathrm{K} 1 / \\
3)\end{array}$ & 92.54 & 90.87 & 92.05 & 91.81 & \\
\hline $\begin{array}{l}\mathrm{k} 2=(\mathrm{K} 2 / \\
3)\end{array}$ & 92.80 & 92.65 & 91.55 & 93.61 & \\
\hline $\begin{array}{l}\mathrm{k} 3=(\mathrm{k} 3 / 3 \\
)\end{array}$ & 91.59 & 93.42 & 93.34 & 91.51 & \\
\hline $\mathrm{R}$ & 1.21 & 2.55 & 1.79 & 2.10 & \\
\hline $\begin{array}{l}\text { Optimals } \\
\text { cheme }\end{array}$ & $\mathrm{A}_{2}$ & $\mathrm{~B}_{3}$ & $\mathrm{C}_{3}$ & $\mathrm{D}_{2}$ & \\
\hline Order & BDCA & & & & \\
\hline
\end{tabular}

From table 2, we can see that the range(R)of $\mathrm{pH}$ value, HRT, DO, MLSS were $1.21,2.55,1.79,2.1$, so the influence factor sequence on the effect of COD removal from large to small is HRT (B), MLSS (D), DO (C), pH (A), Through Orthogonal design, the optimum combination(B3D2C3A2), which is HRT (B):18h, MLSS (D): 5g/L, pH:8,DO:4 mg/L respectively. 
TABLE 3 ORTHOGONAL EXPERIMENTAL RESULTS OF AMMONIA-NITROGEN

\begin{tabular}{llllll}
\hline Number & $\mathrm{pH}$ & $\begin{array}{l}\text { HRT(h } \\
\text { ) }\end{array}$ & $\begin{array}{l}\mathrm{DO}(\mathrm{m} \\
\mathrm{g} / \mathrm{L})\end{array}$ & $\begin{array}{l}\text { MLSS( } \\
\mathrm{g} / \mathrm{L})\end{array}$ & $\begin{array}{l}\text { Removal } \\
\text { rate(\%) }\end{array}$ \\
\hline 1 & 7 & 12 & 2 & 4 & 90.07 \\
2 & 7 & 15 & 3 & 5 & 91.91 \\
3 & 7 & 18 & 4 & 6 & 91.39 \\
4 & 8 & 12 & 3 & 6 & 90.84 \\
5 & 8 & 15 & 4 & 4 & 93.88 \\
6 & 8 & 18 & 2 & 5 & 92.79 \\
7 & 9 & 18 & 4 & 5 & 91.67 \\
8 & 9 & 12 & 2 & 6 & 91.41 \\
9 & 9 & 15 & 3 & 4 & 90.16 \\
K1 & 273.37 & 272.32 & 274.27 & 274.11 & \\
K2 & 277.51 & 275.95 & 272.91 & 276.37 & \\
K3 & 273.24 & 275.85 & 276.94 & 273.64 & \\
k1=(K1/3) & 91.12 & 90.77 & 91.42 & 91.37 & \\
k2=(K2/3) & 92.50 & 91.98 & 90.97 & 92.12 & \\
k3=(k3/3) & 91.08 & 91.95 & 92.31 & 91.21 & \\
R & 1.42 & 1.21 & 1.34 & 0.91 & \\
Optimal & $\mathrm{A}_{2}$ & $\mathrm{~B}_{2}$ & $\mathrm{C} 3$ & $\mathrm{D} 2$ & \\
scheme & & & & & \\
Order & $\mathrm{ACBD}$ & & & & \\
\hline
\end{tabular}

From table 3, we can see that the range(R) of $\mathrm{pH}$ value, HRT, DO, MLSS were1.42,1.21,1.34,0.91, respectively. so the influence factor sequence on the effect of COD removal from large to small is HRT (B), MLSS (D), DO (C), $\mathrm{pH}(\mathrm{A})$, Through Orthogonal design, the optimum combination(A2C3B2D2), which is HRT (B):15h, MLSS (D): 1.42g/L, pH:8, DO:4 mg/L, respectively.

\section{CONCLUSIONS}

The SDMBR has a good performance of the removal efficiency performance on the high ammonia nitrogen wastewater during the start-up and operation period.

MLSS, DO, HRT and $\mathrm{pH}$ is the main influencing factors of high ammonia nitrogen treatment reactor, the influence order of different factors to the COD removal rate was HRT $>$ MLSS $>$ DO $>\mathrm{pH}$, he influence order of different factors to the NH4+-N removal rate was $\mathrm{pH}>\mathrm{HRT}>\mathrm{DO}>\mathrm{MLSS}$, respectively.

According to the reactor operation period of high ammonia nitrogen wastewater treatment effect and the Orthogonal experimental results of ammonia-nitrogen and COD, the optimal process conditions for the high ammonia nitrogen wastewater treatment by SDMBR reactor were determined to be: $\mathrm{pH}, 8$; DO,4mg/L; MLSS, 5g/L; HRT,15h.

\section{REFERENCES}

[1] G. Jun Sheng Feng, HaiFengXu, Li Hua Zhao. Removal of high concentration ammonia by nano-denitrification agent and ultrasound stripping [J Journal of environmental engineering, 201, 01:177-182.

[2] SUN Hong-wei1,YOU Yong-jun, PENG Yong-zhen, WANG Shuying. The process characteristics of the pulsed-SBR for advanced nitrogen removal via nitrite pathway from landfill
[3] leachate China Environmental Science. 2014,05:1139-1144.

[4] Yang Shuai,YangFenglin, FuZhimin, etal.Comparison between amoving bed membrane bioreactor and conventional membrane bioreactor on organic carbon and nitrogen removal [J].Bioresource Technology, 2009, 100(8): 2369-2374.

[5] Gui Yongxin Huang Tianyin Li Wenwei,Yao Jia. Operating process parameters and performance of aerobic granular sludge 